\title{
¿Por qué nos escogió a nosotros para la práctica coral, si somos tan indisciplinados?
}

Volumen $5 \mathrm{~N} .042$ enero - junio de 2017

ISSN: 0122-4328

ISSN-E: 2619-6069 pp. $85-100$
Why Were We

Chosen for Choral

Practice if We Are So

Undisciplined?

\author{
Por que fomos \\ escolhidos para \\ a prática coral \\ se somos tão \\ indisciplinados?
}

José Ignacio Bolaños Motta*

Mónica Alexandra Pérez Rodríguez**

Fecha de recepción: 14-12-2016

Fecha de aprobación: 26-09-2017

\section{PARA CITAR ESTE ARTÍCULO}

Bolaños, J. y Pérez, M. (2018). ¿Por qué nos escogió a nosotros para la práctica coral, si somos tan indisciplinados? Nodos y Nudos, 42, 85-100.
* Licenciado en Música y Magister de la Universidad del Cauca. Actualmente se desempeña como docente en la Universidad de los Llanos en Villavicencio (Meta) en el área de investigación en Educación y Pedagogía. jbolanos@unillanos.edu.co Licenciada en Música y maestra en Canto Lírico de la Universidad del Cauca. Maestro del Conservatorio de la Orinoquía. monickpr@hotmail.com 


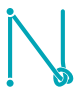

Volumen $5 \mathrm{~N} .{ }^{\circ} 42$ enero - junio de 2017 ISSN: 0122-4328 ISSN-E: 2619-6069 pp. $85-100$

\section{RESUMEN}

A partir de una propuesta didáctica y pedagógico-musical, el presente escrito reflexiona acerca de la práctica de la música para coro, a partir del ejercicio se desarrolló realizado con la población infantil del curso 5. ${ }^{\circ} \mathrm{B}$ de la Escuela Normal Superior de Popayán, una comunidad que en determinado momento de su periodo escolar se vio enfrentada a problemas graves de convivencia escolar. Fue entonces cuando se acudió al uso de la euritmia steineriana como metodología para la enseñanza de la música, mediante la cual se puso de manifiesto la importancia de los espacios de aprendizaje, la lúdica y el movimiento. Desde este enfoque pedagógico se dio una mirada a su influencia sobre la convivencia escolar y los imaginarios de libertad interior; categorías que emergieron del mismo contexto escolar una vez sistematizada la información. Se espera que este trabajo constituya un aporte para la formación de licenciados en música maestros en Colombia, a partir de experiencias pedagógicas que, sin perder la especificidad de la enseñanza, en este caso en lo referente a de la práctica coral, establecen conexión con la vida de los niños y de sus problemáticas, en perspectiva de una formación integral.

Palabras clave: enseñanza de la música; convivencia escolar; práctica coral; corporeidad; euritmia; cartografía

\section{ABSTRACT}

Based on a didactic and pedagogical-musical proposal, this paper reflects on the practice of choir music, starting with the exercise developed with the children from class 5B at Escuela Normal Superior de Popayán, a community that, at a certain point during the school year, was faced with a serious issue of coexistence at school. It was then that Steiner's eurythmy was used as a methodology for teaching music, which highlighted the importance of learning spaces, play, and movement. From this pedagogical approach, the paper takes a look at its influence on school coexistence and the imaginaries of inner freedom, categories that emerged from the same school context once the information was systematized. The hope is that this work will contribute to the training of music teachers in Colombia, based on pedagogical experiences that, without losing the specificity of teaching, in this case regarding choral practice, establish a connection with the life of children and their problems, with the perspective of a comprehensive education.

Keywords: teaching music; coexistence at school; choral practice; corporeity; eurythmy; cartography

\section{RESUMO}

A partir de uma proposta didática e pedagógico-musical, o presente texto reflete sobre a prática da música para coro, com base no exercício realizado com a população infantil da quarta série da Escola Normal Superior de Popayán, uma comunidade que em um momento de seu período escolar esteve envolvida em sérios problemas de convivência escolar. Utilizou-se a euritmia steineriana 
como metodologia para o ensino da música, por meio da que manifestou-se a importância dos espaços de aprendizagem, a lúdica e o movimento. Desde esta abordagem pedagógica, analisou-se sua influência sobre a convivência na escola e os imaginários de liberdade interior, categorias que surgiram do contexto escolar uma vez sistematizadas as informações. Espera-se que este trabalho seja uma contribuição para a formação de professores de música na Colômbia, a partir das experiências pedagógicas que, em relação específica com o ensino relacionado com a prática coral, estabelecem conexão com a vida das crianças e seus problemas, em perspectiva de uma formação integral.

Palavras-chave: ensino da música; convivência escolar; prática coral; copropiedade; euritmia; cartografia

\section{Introducción}

Este escrito se basa en una propuesta de investigación en el arte musical (Durán, 2011, y en el trabajo llevado a cabo en una práctica de enseñanza coral con la población infantil del curso $5 .^{\circ}$ B de la institución educativa Escuela Normal Superior de Popayán, desde la disciplina artística de la música, tomando como base didáctica el despliegue de la corporeidad. Los supuestos teóricos partieron de la propuesta educativa del pedagogo Alemán Rudolph Steiner, cuya propuesta hoy se denomina pedagogía Waldorf (Morales, 2009). Valga aclarar que la propuesta no tuvo como propósito evidenciar la vigencia del mencionado pedagogo ante determinado contexto de la Escuela Básica Primaria, sino que a partir de un posible caso de estrés escolar (como problema de investigación) se encontró que era necesario desarrollar una estrategia pedagógica basada en la euritmia (Marcos, 2014). Este enfoque didáctico fue planteado por la pedagogía Waldorf, con miras a atender determinadas necesidades de la población; se puede definir como un arte del movimiento, su nombre procede del griego eu, 'verdadero', 'armónico', y ritmia, que significa 'ritmo'. En este orden de ideas también se pensó desde un principio en la posibilidad de desarroIlar una educación musical-coral otra, entendiéndose la palabra otra como una práctica coral ajena a las tradicionales prácticas de coro realizadas en los conservatorios de música, donde el estudiante se caracteriza por su inmovilidad y autorrestricción del movimiento como parte de la propuesta escénica'. Asimismo, es de notar que aunque muchas prácticas generadas por los euritmistas se ejecutan a través de instrumentos como el piano y el órgano (Morales, 2009), de origen cultural europeo, las prácticas realizadas se musicalizaron con instrumentos latinos como el cuatro, la guitarra, el güiro, la charrasca, las maracas, la conga y el acordeón. En la misma perspectiva se acudió al uso de distintos ritmos colombianos como el joropo, el bambuco, el porro, el vallenato y varias cumbias. Lo anterior como una forma de caracterizar y desarrollar en las aulas de la básica primaria la apropiación de los ritmos populares colombianos, para con ello generar una transmisión musical de la cultura nacional.

Para entrar en los problemas de la infancia, ha sido motivo de reflexión el hecho de que el mundo ha venido cambiando a un ritmo demasiado vertiginoso; lo cual ha generado cambios notables en los estudiantes y sus problemáticas, a tal punto que podemos decir que en la actualidad existe una nueva niñez, producto de la hiperrealización que se cierne sobre el concepto común de infancia (Narodowski, 2013). A ello se suma que en las ciudades grandes e intermedias del sistema capitalista los padres de familia se encuentran ante la necesidad, escasamente satisfecha, de vincular

1 Ello a través de un repertorio musical latinoamericano desarrollado y como una nueva forma de desarrollar la práctica coral, formato ampliamente desarrollado en España y Venezuela (Morales, 2009) y escasamente practicado por la escuela tradicional colombiana. 
a sus hijos a nuevas propuestas educativas y nuevos maestros, para lo cual se hace indispensable un re-dimensionamiento de la escuela, que ya se encuentra en crisis. Mejía (2014), por su parte, agrega que nos encontramos ante una despedagogización del oficio del maestro, por cuanto a este se le indica un lugar en la sociedad como funcionario estatal.

En consecuencia, en el presente trabajo, las prácticas musicales o las didácticas generadas desde el campo de la disciplina artística, como es el caso de la música y en particular el canto coral, plantean una interesante propuesta que permite pensar al maestro de una manera distinta a la presunta complicidad de la educación -desde los ámbitos del deporte, las artes y las disciplinas clásicas- como agente que permite o estimula el desconocimiento del ser emocional, las inclinaciones y de la inteligencia sensorio-motriz del niño (Gardner, 1997). Este hecho se encuentra muy marcado por el sistema tradicional vigente en Colombia, incluso dentro del sistema misional de las escuelas normales colombianas, por lo cual Quiceno (2015), concluye que están ancladas en el siglo xIx. Basados en que es posible dar un tratamiento a este problema a través de nuevas formas de hacer escuela, en el presente estudio se dimensionaron áreas como: la didáctica, la lúdica, y la corporeidad, todas enfocadas hacia el desarrollo de competencias ciudadanas, de tal forma que se lograsen generar nuevos aportes a la forma de dimensionar la escuela en nuestro país.

\section{Un poco de historia sobre el tema}

Como se anotó, la propuesta desarrollada en el proyecto como metodología de enseñanza fue el sistema de formación musical holistica e interactiva del pedagogo alemán Rudolf Steiner, hoy llamada pedagogía Waldorf -no en vano existen cerca de 1026 escuelas Waldorf repartidas en 59 paises del mundo- (Quiroga, 2014). Este modelo de escuela se basa en una serie de principios espirituales y filosóficos que distan de los utilizados en el marco de la enseñanza convencional. Su metodología se encamina a que el ser humano encuentre la esencia de su ser a través de la creatividad, el arte y el movimiento, desde una comprensión global y humanística (Wallerstein, 2006), basándose en los conocimientos íntimos de su naturaleza, y mediante el desarrollo de una estructura de respeto por los ciclos de la vida, sus intenciones y los vínculos humanos, en pro de una transformación de la persona a partir de la educación tradicional, hasta lograr construir una estructura viva de conocimiento.

Aun cuando la propuesta de esta pedagogía pretende que el niño alcance el desarrollo de sus doce sentidos (Errenst, 2012), a la que más se le da uso en este escrito es a la euritmia, pues en esta investigación sobre la actividad social y artística (Cerón, 2012), se partió del interés en fortalecer la relación pedagógica y corpórea, en los espacios que comparten el maestro y el estudiante. El concepto de euritmia nació en 1912, época en que su creador empezó a desarrollar las pautas necesarias para la configuración de este nuevo enfoque artístico, que se consolida hacia 1919, cuando se fundó la Escuela Waldorf (Morales, 2009). Dicha propuesta se llevó al currículo como parte de la didáctica de la enseñanza de áreas académicas de una escuela en la cual se dimensiona la música a través del uso de canciones y juegos de grupo, como se evidencia a continuación:

El día y sus actividades tienen un ritmo y estructura regular desde que los niños llegan hasta que se marchan. Hay un equilibrio entre el trabajo diario que ha de hacerse: cuidar la casa, hace pan, lavar la ropa etc., y los sencillos trabajos manuales de tejer, tallar madera, bordar y coser. Hay que barrer, rastrillar las hojas fuera e incluso cuidar un pequeño jardín. Están además las fiestas que se celebran, contar cuentos, cantar canciones y hacer juegos en grupo. (Clouder y Rawson, 2002, p. 51).

Esta propuesta de metodología de enseñanza se usa hoy en día en más de 50 paises, sin embargo en Colombia aún no se ha desarrollado lo suficiente, debido a la primacía del sistema tradicional, en el que la música y en general las artes no forman parte de los fundamentos de la academia. Muy a pesar de una aparente flexibilidad curricular, en los programas artísticos, se observa en las escuelas una preponderancia de tiempos para las áreas del lenguaje, las ciencias naturales y las matemáticas (Muñoz, 2005). De manera contraria, el despliegue de la plástica y de otras prácticas artísticas desempeña un papel predominante en la pedagogía Waldorf. No obstante, este modelo no excluye 
disciplina alguna - que sí es problema en otras tendencias o modelos educativos-, pues en el trabajo steineriano se equilibra saludablemente el trabajo intelectual con las actividades artísticas, y se genera una complementariedad entre lenguajes y prácticas estéticas con modelos teóricos y científicos. La complementariedad didáctica fue de gran ayuda para el problema educativo afrontado en esta investigación (Pasek, 2008).

\section{Sobre la euritmia y la música coral}

Respecto al canto coral, es importante en la actualidad el trabajo del maestro Alberto Grau por sus aportes a esta modalidad musical. Dentro de su obra se destacan las composiciones para diversos formatos corales, entre ellos, el coro infantil, en el cual se destaca el uso de la euritmia. El maestro Grau ha aportado al estudio de la tradición de este arte, clasificándolo en tres momentos representativos. En el primero se encuentra la euritmia sonora simple, consistente en el empleo de movimientos corporales leves que involucran hombros, cabeza y brazos, a los cuales no se genera ningún sonido rítmico ni movimiento amplio, sino que funcionan como complemento de la línea melódica. Para ejemplificar un poco, se trata de cantar una nota larga complementada por una acción corporal como el desplazamiento lento de cabeza u hombros. En el segundo, se encuentra la euritmia coreográfica, que se divide en dos partes: la aleatoria y la rítmica. La aleatoria se apoya en movimientos que refuerzan el texto y generan una atmósfera especial, pero sin una métrica determinada. Por el contrario, la rítmica sí lleva una métrica determinada, y cumple similarmente las demás funciones de la aleatoria. Por último, se encuentra la euritmia integral, que aparte de utilizar elementos de la coreográfica, también genera sonidos, por ejemplo, de chasquidos, de palmas o de manos contra las piernas y el pecho, o de los pies. Durante el trabajo realizado con los niños del grado $5 .^{\circ}$ B se hizo una mezcla de las tres tendencias expuestas, dando preponderancia a la euritmia coreográfica, mezclada con la euritmia integral y también la euritmia curativa propuesta para uso terapéutico. Parte de esta actividad queda se presenta en las imágenes que componen la tabla 1 expuesta en el siguiente apartado.

\section{Sobre la euritmia y sus modalidades}

La palabra euritmia se compone del prefijo eu-, que aúna varios conceptos como lo bello, lo bueno y lo verdadero, y de ritmia, que significa 'ritmo' (Pérez, 2015). Este término también se entiende como el arte de moverse de forma armoniosa y expresiva, buscando siempre la belleza en cada movimiento, para poder expresar claramente los distintos estados de ánimo que tiene el ser humano, de manera que se convierte en una forma de comunicación. En los últimos años la pedagogía Waldorf se ha asumido como una estrategia didáctica de aprendizaje, y se define como "un género de lenguaje mudo y visible, un lenguaje que aunque aparece de forma gestual, con movimientos corporales, no debe ser confundido con pantomima, ni ser considerado como el arte de la danza" (Fernández, 2007, citado por Morales, 2009, p. 11). Ante esta permanencia y no permanencia en las distintas disciplinas artísticas, la euritmia ha venido implementándose como metodología en el teatro y en la danza, de lo cual han nacido novedosas propuestas como la danza-teatro o la música como teatro (Restrepo, 2005), y de manera reciente -como es el caso del presente trabajo- se ha usado a modo de recurso didáctico para la enseñanza de la música.

Esta estrategia didáctica, aplicada a la población infantil del grado quinto, ofreció la posibilidad de interrelacionarse de manera corpórea con las leyes básicas del ritmo, a través del movimiento corporal. A partir de lo ejercitado se llegó a reconocer e interiorizar los elementos constitutivos de la música; entre muchos otros, las tímbricas, el ritmo, las escalas, y las temáticas de la canción, además de exteriorizar la palabra no solo a través del canto sino también del cuerpo. De esta manera se asimila la poética, la dramática o la lírica misma de la canción, y se dibuja el movimiento sonoro a través de los brazos, las manos y las piernas. Esto permite dimensionar el cuerpo a modo de un instrumento que hace que la palabra o la música no solo sea audible sino también visible, y lleva a un plano más amplio la expresión del arte musical y gestual. Al respecto, el doctor Frans Carlgren (1989) opina que: 
Estamos habituados a formas de expresión que traducen la poesía o el discurso en movimientos que están determinados por el contenido, como la danza expresiva, el teatro, la mímica o la coreografía de grupos. La euritmia parte de los sonidos del lenguaje, es decir, de las vocales y las consonantes. Cuando pronunciamos un sonido, en nuestro interior tiene lugar una especie de invisible "ademán de la voluntad", y éste es el que adquiere expresión visible en el movimiento euritmico. Cada vocal y cada consonante tienen su movimiento especifico. (p. 34).

A lo largo de la historia, o quizás de la tradición de este concepto, se encuentran tres modalidades de euritmia desarrolladas hasta la actualidad. La diferencia entre ellas consiste en el uso que se le da a cada una, pues se hace referencia a las euritmias artística, pedagógica y curativa. La euritmia artística corresponde a un trabajo en el que participan elementos como la coreografía, la iluminación, la música, las recitaciones o dramatizaciones en vivo y los vestidos con velos de colores (Carlgren, 1989). Este último fue el único modelo de euritmia que no se tuvo en cuenta en esta propuesta. En otro momento se dio uso a la euritmia pedagógica o escolar, una las ideas motoras del modelo aplicado por Steiner en su primera escuela Waldorf como parte de su currículo. En este modelo de trabajo se toma como eje fundamental el deseo de educar para y desde la corporeidad en términos de establecer el dominio sobre la lateralidad; desarrollo de la coordinación motora, gruesa y fina; interiorización del ritmo; conciencia de la postura, entre otros elementos. De igual manera se hace uso de ambientes amplios y propicios para la lúdica musical. Este modelo se usó ampliamente dentro de la investigación realizada puesto que las piezas musicales que formaban parte del repertorio hacian que los niños entendieran los movimientos euritmicos como parte al mismo tiempo de un juego y de una danza. Esta didáctica se sustentó en la idea del doctor Carlgren (1989), quien dice que: "En los primeros años escolares, la euritmia viene a satisfacer la afición natural del niño por el movimiento. En los cursos superiores, los alumnos pueden encontrar, partiendo de las energías conscientes despiertas, posibilidades de una creación artística independiente" (p. 35). Finalmente, la euritmia curativa es una propuesta que busca establecer una armonización entre el cuerpo y la parte etérica del ser humano; acto que se espera alcanzar por medio del movimiento armónico de un grupo de mímicas y gestos, en donde el paciente idealmente cura su patología a través del movimiento.

Luego de las acciones propuestas se pasó a hacer un trabajo de observación de los cambios surgidos en la población. Se generó así una reflexión investigativa que toma como objeto de estudio este grupo de prácticas escolares, algunas de las cuales se expondrán a continuación.

\section{Movimientos eurítmicos desarrollados en el proceso investigativo}

Como elemento principal de esta metodología, los gestos corporales desarrollados a lo largo del repertorio infantil se encuentran propuestos desde los principios de la euritmia steineriana como una manifestación del cuerpo y del alma. En consecuencia, cada movimiento posibilita -desde la óptica de Steiner- la sanación de un grupo de problemáticas y complejidades posibles en la psique humana (tabla 1).

Tabla 1. La estudiante Paula Andrea Solano Morales realiza algunos movimientos eurítmicos.

En este gesto se expresa el acto de sonreír, como una acción mímica relacionada con la letra de la canción titulada Ola loca, en el momento en que se hace la expresión:

Ay ola, ola loca no te vayas a escapar Con tu risa salada quiero volver a jugar... 
En la fotografía está expresado el acto de subir, como una forma de señalizar la popular canción infantil Samba Lele. En la imagen se observa el momento en que se canta:

Quiso subir a la luna, Y se cayó en la laguna...

El gesto relacionado es el de la ondulación de la ola, expresión realizada con el brazo como parte de la canción Ola loca, en el estribillo donde se dice:

Hay una ola loca pegadita de la mar Hay una ola loca que no para de jugar...

En la reconocida canción de Luis Pescetti titulada Tiburón- Tiburón se mueven las caderas a lado y lado de los escolares, en el momento que se canta el verso:

Sal del agua mujer, y ven conmigo a bailar, que el tiburón te va a comer...

En este gesto se ubica la vocal U subiendo los brazos estirados hacia arriba y ubicados de forma paralela. Esta forma de señalizar la vocal con el cuerpo fue propuesta por el mismo Rudolph Steiner. Este gesto se usó en la parte final de la canción, donde se dice:

En la isla encontré un enorme avestruz, Que comía Bambú y cantaba con U
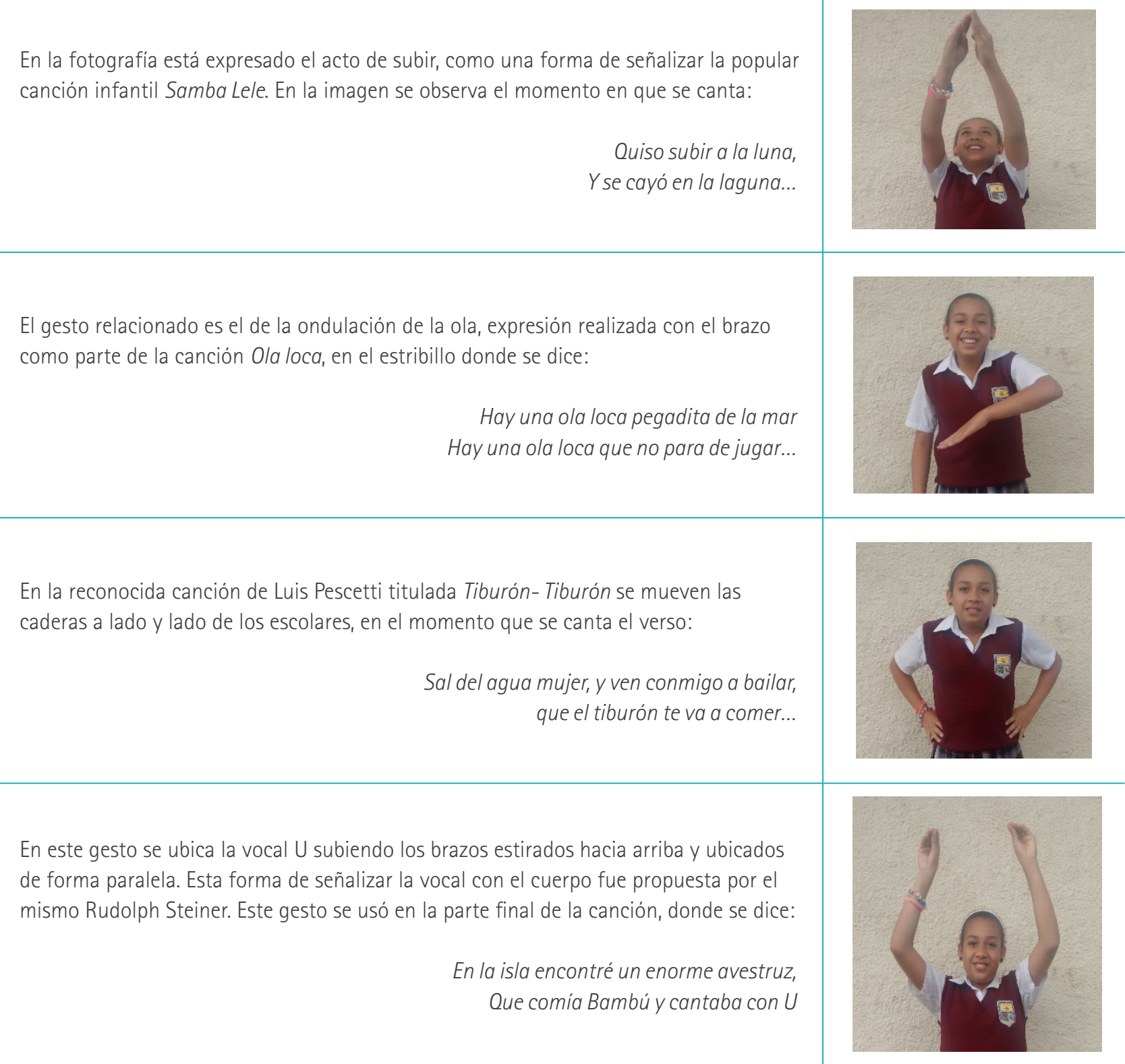

Fuente: Pérez (2015).

Todos los movimientos expuestos en las anteriores fotografías pueden ir acompañados de movimientos y desplazamientos con los pies, lo que lleva al reequilibrio y estabiliza el ritmo. Con el uso de las vocales, la gesticulación se retiene, o cual impresiona la concentración hacia el interior, armonizando y tranquilizando el pulso y la respiración.

Dentro de la propuesta investigativa realizada se manejaron las vocales desde la pedagogía Waldorf. Estas se utilizaron en el repertorio cuando se tomaron como base las posturas preestablecidas desde las escuelas o las pedagogías Waldorf, a modo de una vivencia interior, armoniosa y tranquilizante para la población infantil. De esta manera se generó un ambiente de aprendizaje desde el cual se lograron una serie de hallazgos o categorías emergentes, que se expondrán a continuación.

\section{La influencia del aula escolar sobre la enseñanza de la música}

La escuela tradicional se ha encargado de generar medidas de control en torno al cuerpo del estudiante. 
Esas formas de disciplina física se han enfocado en la limitación del movimiento del niño, pues de parte del mundo adulto siempre se ha buscado la posibilidad de generar una economía de los derechos (Foucault, 2003) y de la libertad del cuerpo del estudiante. En el marco del proceso de formación, la música como disciplina artística de conocimiento no ha estado desvinculada de esta división disciplina-cuerpo que podriamos denominar problemática. Al respecto, Shifres (2012) nos dice:

Todo aquello que no es sonoro pasó a ser, por definición, extramusical. Así, se consolidó la tendencia de escisión de la música respecto principalmente del movimiento corporal, por un lado, y de la narrativa y de la expresión metafórica lingüistica, por el otro, y elevó al estatus de extraordinarios a fenómenos basados en vinculaciones sensoriales y semánticas entre modalidades perceptuales diversas (desde la sinestesia, pasando por diferentes tipos de relaciones transmodales hasta la metáfora y la comprensión transdominio). (p. 6).

Lo anterior ocurre en la búsqueda clásica de generar un pensamiento y una conducta adecuados en el estudiante, para tal o cual fin cultural. En términos de la escolaridad o de los modelos pedagógicos ejercidos en la Escuela Normal Superior de Popayán Básica Primaria, institución en la cual se llevó a cabo este proyecto, a través de la observación directa sobre las prácticas se pudo evidenciar que la disciplina escolar ejercida hacia los 37 estudiantes del curso 5. $B$ se encuentra en gran medida en contradicción con la naturaleza misma del niño, pues durante el periodo de 8 a 11 años de edad, se suele estar en una búsqueda de movimiento, de acción; en otras palabras, de una exploración de la propia corporeidad. Contrario a suplir la necesidad del movimiento por parte del niño o niña, la escuela se ha encargado de mantener al estudiante dentro de un estado de quietud y de silencio, para direccionar así su cuerpo, mente y pensamiento hacia un aprendizaje memorístico o bancario (Freire,1975). En este sentido, vale aclarar que aunque el aprendizaje de las canciones fue memorístico, el proyecto también abordó la interiorización de un repertorio con rítmicas del contexto para el aprendizaje, mas no de la memorización repetitiva e instrumental (Díaz Barriga, 2005).
Una dificultad didáctica en la escuela surge cuando el cuerpo del estudiante es invisibilizado por una educación basada en el sistema clásico, acentuada en el uso exclusivo de tiza y tablero, lápiz y cuaderno (D de Campo \# 3, apunte \# 1). A lo anterior se agrega, por ejemplo, que la asignatura Educación Física, que históricamente se ha configurado como el espacio académico para el cuerpo y el movimiento, no ha tenido profesores regulares dedicados al trabajo de aula; este hecho se debe en gran medida a las politicas académicas ejercidas por una institución que se sabe anclada en el siglo xIx (Quiceno, 2015).

Un factor que incide directamente sobre el desempeño académico de un niño o una niña es precisamente la triangulación entre la mente del niño, su cuerpo, y la relación de este con el aula escolar o los espacios de clase (véase la figura 1). En este punto se advierte que la institución posee una dificultad con respecto a las instalaciones, ya que no fue construida para albergar el número de población actual. Gracias a la evolución de los sistemas educativos gestados en los siglos xx y XXl, se han logrado algunos avances en torno a la forma como se ha de distribuir el salón de clases, pues según la norma técnica colombiana de construcciones escolares (Ministerio de Educación Nacional, 2006), el espacio por estudiante debería ser de $1,80 \mathrm{~m}^{2}$, o en caso eventual y como mínimo, de $1,65 \mathrm{~m}^{2}$, ya que de esta manera se logra una mejor movilización e interacción con el medio.

Figura 1. Triangulación mente-cuerpo-aula Mente del niño

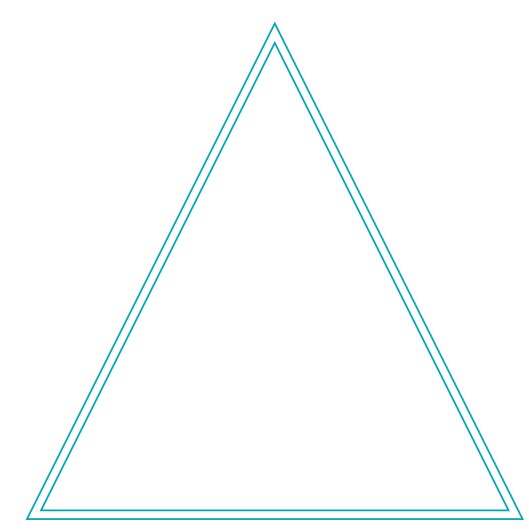

Cuerpo Aula

del niño escolar 
Fotografía 1. Instalaciones del curso quinto de primaria

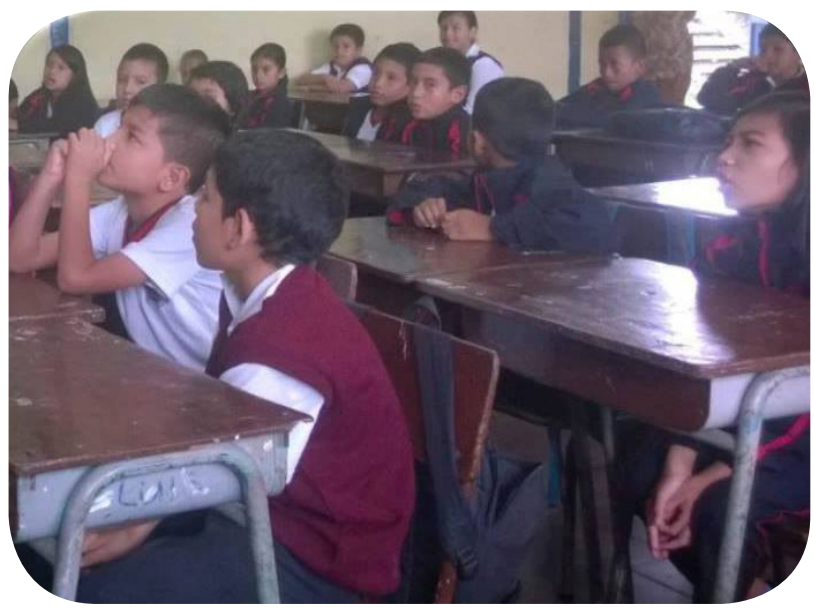

Fuente: Pérez (2015).

Contrario a lo anterior y sin la necesidad de tomar medidas de longitud, en la investigación se evidenció que en esta escuela existe una limitante en términos del espacio, tanto para los niños como para la docente. En consecuencia, durante las jornadas educativas los cuerpos de los estudiantes se encontraban muy limitados dentro del espacio permitido por el pupitre ocupado (Ácaso, 2013), el del compañero del lado, y el del compañero de atrás; en otras palabras, el salón de clase resulta demasiado pequeño y no permite la suficiente distancia entre los estudiantes. Esto se evidencia cuando un estudiante debe pedir permiso a su compañero de atrás para poder salir de su lugar de estudio ( $D$ de Campo \# 3, apunte \# 1). Por otro lado, el espacio disponible para la movilidad de la docente también es reducido, lo cual hace que muchas veces ella (en el aula escolar y durante la jornada de clase) se vea atrapada entre los primeros pupitres y el tablero del aula. En los salones de clase la distribución de pupitres generalmente se maneja de diversas maneras. En el caso del curso 5. ${ }^{\circ} \mathrm{B}$, donde se llevó a cabo esta investigación, los pupitres se organizan para que los estudiantes se sienten por parejas, como se puede observar en la fotografía 1. En este sentido, el pupitre se configura como uno más de los elementos del aula escolar (Zuluaga, 1999), en cuanto órgano de coerción sobre el movimiento del estudiante, y también a modo de herramienta propia de la escuela tradicional, destinada a inmovilizar a los niños. Si bien los pupitres usados en 5. ${ }^{\circ}$ B son individuales, están pegados de manera adyacente, debido al reducido espacio en relación con el número de estudiantes. Como resultado, el cuerpo del escolar se encuentra forzosamente en dirección hacia sus útiles y hacia el tablero durante toda la jornada académica ( $D$ de Campo \# 3, apunte \# 1). Es muy probable que este fenómeno se deba a las necesidades que afronta la escuela pública colombiana por la exigencia de cumplir con los estándares de cobertura educativa, lo cual lleva casi al hacinamiento. Sumado a lo anterior, la institución hace un fuerte énfasis en la ya mencionada quietud del niño, esto se evidencia a través del discurso institucional del manual de convivencia, de sus docentes, y de los normalistas practicantes o maestros en formación, ya que se espera que el niño no se "levante de su puesto", que se "esté callado", que "no haga bulla" con las mesas o las sillas, y que en el momento de buscar la caneca de basura o el baño, lo haga bajo la condición de generar el "mínimo ruido" y con "mucho cuidado" (D de Campo \# 3, apunte \# 1). De este modo, puede ocurrir que los docentes -nos referimos en general al proceso pedagógico- crean erróneamente que han captado la atención de los estudiantes hacia las temáticas de la asignatura, cuando lo que realmente existe es un sometimiento a través del poder conferido a la institución por medio de la habituación de sus costumbres cotidianas (Berger y Luckmann, 1995).

Para aportar a una posible solución a este fenómeno de trabajo individual por asignaturas, durante los últimos años viene tomando mucha fuerza el trabajo interdisciplinario en las propuestas escolares latinoamericanas, no solo en cuanto al trabajo investigativo sino también en cuanto a las prácticas escolares. Por esta razón también se realizó un proyecto interdisciplinario en donde se vinculan la práctica coral, el ejercicio corporal y de una u otra forma, la plástica. A partir de las observaciones llevadas a cabo durante el comienzo de este proceso, se determinó que era posible generar una propuesta musical en la que se integrase la clase de música y el ejercicio físico-corporal y gestual, acompañados a su vez de manera intrínseca con el aprendizaje de los elementos constitutivos de la música (Toch, 2001): el ritmo, la armonía, 
la melodía y la afinación, implícitos en la euritmia, la enseñanza de la técnica vocal y en el aprendizaje de las canciones infantiles.

Dicho aprendizaje, aunque es memorístico, no es explícitamente mental, pues, como se pudo observar, el ejercicio de la memorización forma parte de las consecuencias del trabajo generado en el trabajo musical con la didáctica de la euritmia. Ahora bien, desde el principio se decidió que uno de los objetivos del estudio sería la aplicación de la euritmia en el coro infantil, partiendo de una propuesta estética en la que un grupo de gestualizaciones y movimientos corporales, suaves y elásticos, serían realizados con el cuerpo mismo del estudiantado, por ello uno de los primeros trabajos de aula consistió en gestualizar, con las manos y con la voz, los nombres propios de los niños del curso. Otro trabajo didáctico adelantado durante este estudio consistió en generar con ellos una propuesta musical coreográfica, ya que los coristas tuvieron la oportunidad de proponerle sus ideas al director coral. Lo sucedido implica que el estudiante logró dimensionarse a sí mismo en una relación cooperativa y de igualdad con la docente-investigadora y el director de trabajo de grado, quien hacia las veces de guitarrista acompañante. A su vez, respecto a la docente investigadora, implicó evidentemente una re-significación del oficio de director de coro, pues ya no se trata de quien solo dice o señala aquello por hacer, sino de un integrante de coro que dirige los movimientos de manera ejemplificada y comunitaria con sus coristas y con la interpretación vocal (Burkholder, 2008). A ello se agrega la acción de realizar una investigación mientras se desarrolla una propuesta coral.

\section{El coro en movimiento como un imaginario de libertad interior}

A lo largo de la historia educativa la práctica coral infantil se ha enfocado hacia el estudio y el desarrollo de la voz, y en términos de sus variables se organiza por edad, sexo, técnica o repertorio. En dicha práctica se ha visualizado al corista como un ser inmóvil, en muchos casos dotado de un uniforme incómodo, por lo general una toga y portando una carpeta en sus manos con el repertorio de canciones a interpretar. En este punto se puede decir que tanto la carpeta como la toga se constituyen en limitantes para el movimiento que el corista es capaz de realizar. Con el fin de evitar esta situación, el trabajo investigativo se adelantó sin toga y sin carpeta, de manera que el resultado da cuenta de un ejercicio de corporeidad libre de limitantes.

El movimiento del cuerpo dentro de la práctica coral vista como una forma de elaboración o de expresión de libertad (euritmia) en los niños fue uno de los principales hallazgos del trabajo. Aplicar la euritmia al público infantil resulta relativamente nuevo en nuestro contexto, aunque se ha difundidodesde hace unos años en países como España (Morales, 2009) y Venezuela (Morales, 2009). Al respecto, son motivo de reflexión los significados que posee el término disciplina en la escuela, pues se podría decir que existe un significado muy rudimentario o equívoco de este, que hace alusión a una economía del derecho, al movimiento y a la acción de hablar durante las jornadas de clase (Foucault, 2003). Se hace referencia a expresiones de uso escolar cotidiano, como buena disciplina, mala disciplina o indisciplina, términos que dimensionan el sometimiento y la docilidad del estudiante, a través de una ausencia parcial de libertad, en donde es considerado "juicioso" o "disciplinado" el estudiante que permanece en silencio y se está quieto. Por lo contrario, se le llama "desatento" o "indisciplinado" si desea estar en movimiento o realizar algún sonido en el aula de clase que no esté permitido por el docente en ejercicio (D de Campo \# 3, apunte \# 1). Esta forma de poder escolar despliega una represión negativa en términos de la creatividad y de la expresividad (Ácaso, 2013) y, valga la pena agregar, que cuando el niño hace acciones distintas a las propuestas por el docente, es porque quizá las competencias del maestro, en lo referente a las estrategias didácticas, no son suficientes.

A diferencia de lo anterior, en el trabajo realizado en la Escuela Normal Superior de Popayán, uno de los avances del proyecto consistió en que la actividad coral euritmica se asumió como una práctica de libertad en la cual el niño -quien solía estar limitado a nivel mental por el asignaturismo, y a nivel corporal atado a su pupitre- logró encontrar en el arte musical una práctica libertaria. Este hecho se vio evidenciado con la técnica de la cartografía social (Tetamanti y Escudero, 2012) realizada por los niños (véanse las fotografías 2 y 3 ). 
Fotografía 2. Cartografía realizada a los estudiantes del curso.

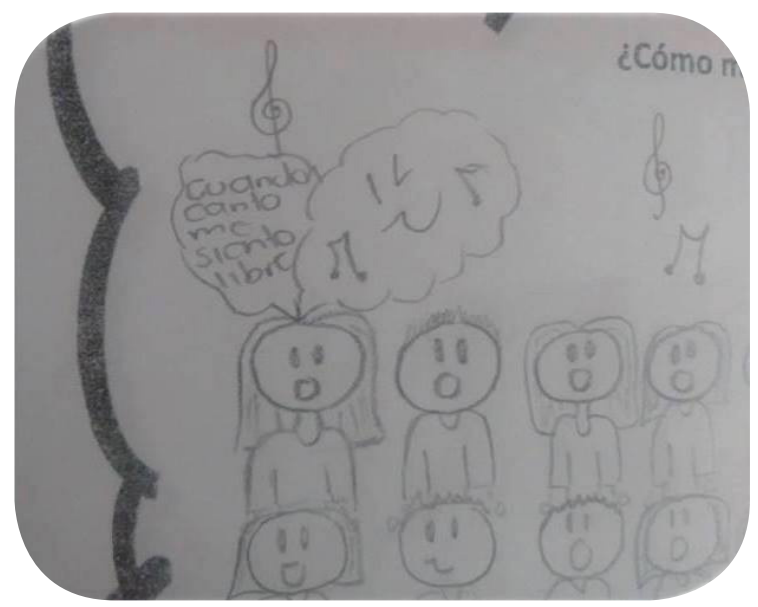

Fuente: Pérez (2015)

Fotografía 3. Cartografía realizada a los estudiantes del curso.

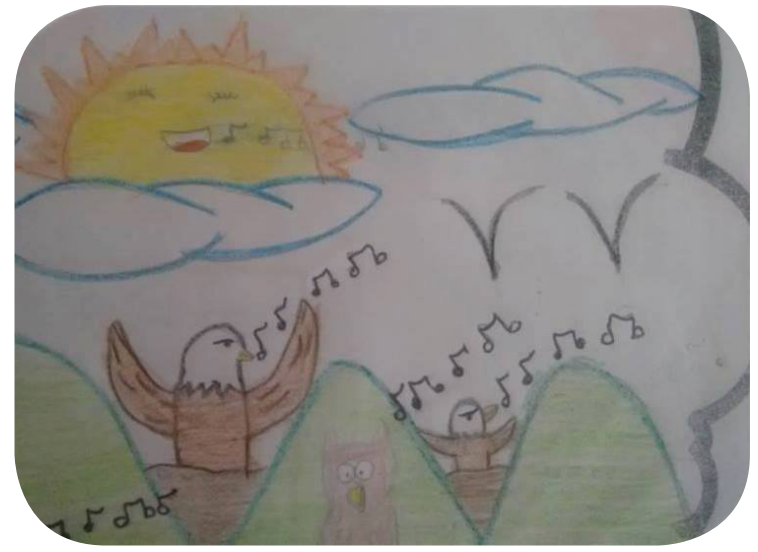

Fuente: Pérez (2015)

Dicha actividad de cartografía social consistió en que cada estudiante expresara cómo se sentía en las clases de música y también que dibujaran sus sentimientos. El resultado fue que se obtuvo un grupo de imágenes relacionadas con el aire: pájaros, águilas, búhos, libélulas, mariposas, nubes y globos (Pérez, 2015), así como las palabras libertad, alegría y satisfacción, plasmadas de manera puntual y escritas en hojas de papel. Todo esto le permitió al grupo de niños y niñas sentirse en un estado de libertad y felicidad, así como interiorizar el repertorio de esta práctica coral euritmica. Las distintas expresiones ubicados en las cartografias ayudaron a dimensionar algunas percepciones en torno a "las clases de música", ya que con sus dibujos la población infantil expresó su sentir sobre "la clase en la cual yo expreso con mi cuerpo", o "soy feliz y me siento libre". Esta categoría se valoró por ver en ella, "el coro en movimiento como un imaginario de libertad interior", pues evidenciaba una dimensión de los sentidos de espacio o territorio (Tetamanti y Escudero, 2012). Vale la pena aclarar que para la obtención de datos dentro de la cartografía social se acudió también a la ayuda de un psicoanalista, de tal forma que a través de un veredicto profesional se lograran establecer las categorias emergentes, gracias a la triangulación: directora de coro e investigadora, director de trabajo de grado y psicoanalista.

\section{La práctica coral eurítmica como estrategia para una convivencia escolar}

Al comienzo de este trabajo investigativo el referente del curso $4 .^{\circ} \mathrm{B}$ (hoy 5. ${ }^{\circ}$ B) era el de ser un grupo con graves problemas de convivencia escolar. Para afrontarlos, se realizaron reuniones con la coordinadora y los padres de familia, otras reuniones con el grupo y una entrevista a la docente en ejercicio, pues el curso estaba afrontando un proceso de "rehabilitación grupal" (D de Campo \# 3, apunte \# 1), del cual se habían encargado varios estamentos de la institución. Al respecto se observó la presencia de casos de matoneo entre estudiantes, además de maltrato físico, verbal y psicológico; esto último también afectó a la docente. Con posterioridad a las primeras visitas y ensayos del coro, se pudo corroborar que existían algunos casos problemáticos en cuanto a la convivencia, como lo mencionaba la docente titular. No obstante, el grupo demostró un gran interés hacia la práctica de la música, y a partir de esto fueron muy pocos los casos en que se tuvo cuenta de hechos violentos. Fue entonces cuando se formuló la posibilidad de hacer una agrupación coral, más allá de la investigación que se venía realizando, hecho al que los estudiantes reaccionaron con sorpresa.

Al respecto, en el diario de campo se consigna el interrogante de varios estudiantes: "¿Por qué nos escogió a nosotros para la práctica coral si somos tan indisciplinados?" (D de Campo \# 3, apunte \# 1). 
Este hecho deja ver que la práctica coral o la música, al igual que otras actividades al margen de las asignaturas de la escuela tradicional, son vistas por el estudiantado como un premio a su "buena conducta" en clase ( $D$ de Campo \# 3, apunte \# 1). En realidad, este fue otro hallazgo en los significados que adquieren las asignaturas para los estudiantes de la escuela. Aunque la propuesta inicial no consistió en generar un proyecto encaminado a evidenciar la forma como la actividad musical genera sentidos de autorreconocimiento y construcciones de ciudadanía en los procesos de desarrollo humano, de manera paralela y con el avance del estudio se evidenció un conjunto de cambios significativos en torno a las relaciones interpersonales de los estudiantes, lo cual, dicho de otra manera, equivale a decir que el trabajo coral y de equipo ayudó en gran medida a fortalecer la convivencia escolar. Este hecho tuvo una incidencia positiva sobre las asignaturas de la escuela tradicional. Lo anterior se pudo evidenciar en la segunda entrevista realizada a la docente encargada del curso, quien afirmó:

Luego de su clase uno ya ve a los niños más concentrados, más relajados, entonces la atención de ellos después de su clase (de la docente de coro), es excelente. Cualquier problema que hayan tenido o que venga de sus hogares, en su clase se les olvida, se acaba, como le decía, su actitud es muy diferente, ya que al estar más relajados, se concentran más, participan más y trabajan más.

Aunque la didáctica de trabajo con el coro en este estudio fue grupal, al igual que el producto final, el aprendizaje musical de cada uno de ellos se generó de forma individual, y se expresó y evidenció a través del cuerpo. La práctica de la euritmia en conjunto con la actividad coral, asumida de manera lúdica y recreativa, ayudó a potencializar las capacidades expresivas y comunicativas en el curso, no solo durante la práctica en cuestión, sino en las demás áreas de su vida escolar. Se notaron cambios en su gestualidad y personalidad; por ejemplo, a la hora de comunicarse con la docente y sus compañeros le dan más importancia a la expresión y la comunicación. De este modo se restó espacio a la intolerancia, al miedo, al matoneo y al estrés escolar.

\section{Sobre la metodología de enseñanza}

Con la realización de las actividades enfocadas al aprendizaje de la música orientada a la actividad coral, se empezaron a desarrollar una serie de clases y talleres en los cuales se trabajó en un repertorio musical latinoamericano previamente escogido, como eje potencial de las cualidades vocales en la población estudiantil. Para alcanzar estos objetivos, en una primera etapa los niños estuvieron sentados en sus pupitres, ya que el espacio proporcionado por la institución no se prestaba para hacer actividades de pie o para mover los muebles en búsqueda de una adecuación del lugar. Luego se indicó a los estudiantes que las manos de la directora serían sustitutas de la voz en actividades como pedir silencio, dar la palabra, pedir actividad o quietud, además de intensidades y velocidades ( $D$ de Campo \# 3, apunte \# 1). De esta manera se omitirian los gritos habituales de las demás asignaturas de la educación tradicional, a los cuales estaban acostumbrados. Asimismo, se pidió para la clase de música un cuaderno lineal, mas no pentagramado, debido a que el objetivo de esta propuesta de enseñanza no era aprender notación musical, sino registrar letras de canciones y demás actividades de clase. Luego de alcanzar algunos consensos, las clases de música manejaron el siguiente esquema de cinco fases:

1. Con el ánimo de mantener en todo momento la atención del público infantil, el proceso contemplaba en su parte inicial el acto de presentar a los niños la canción a manera de cuento.

2. Luego se realizaban los movimientos euritmicos que caracterizaban el cuento para que de esta manera los niños reconociesen la parte del relato o el personaje narrado.

3. Una vez se tenía clara la coherencia entre narración y cuerpo, se realizaba una actividad sin sonido alguno. Esta parte de la clase era meramente gestual.

4. Enseguida se empezó a interiorizar la canción, primero por frases y sin afinación, y luego con voz cantada en compañía de una guitarra. Poco a poco 
se fue relacionando la historia con los movimientos euritmicos, y también la afinación; esto se logró con la ayuda de los aportes metodológicos para la enseñanza de la música para coro (Zuleta, 2013).

5. En busca de una ayuda para afianzar la afinación se utilizó la fononimia de Kodaly con números (Zuleta, 2013), en donde los estudiantes sin saber que cantaban una escala musical solo se divertían con las diferentes posiciones de las manos y su respectivo sonido agudo o grave.

\section{Resultados}

\section{La actividad coral y la euritmia}

Dentro de este trabajo investigativo se logró generar un coro infantil en movimiento (Pérez, 2015), pues en esta práctica coral no se realizó ningún tipo de clasificación o selección de las voces, sino que se incluyó a la totalidad de integrantes del curso. Esto implicó un reto pedagógico para los docentes implicados en este proceso, si bien el desarrollo de esta propuesta de coro se llevaría a cabo de manera independiente de la capacidad previa de los estudiantes para emitir sonoridades afinadas. También se realizaron algunos ejercicios para estimular y potencializar las distintas capacidades requeridas para cantar en un coro, sin que los estudiantes tuvieran que ver directamente con conceptos teóricos o estructuras técnicas que estimularan su desarrollo musical. En este proceso se notó que la acción de hablar más agudo de lo normal, haciendo alusión a imitar a un niño muy pequeño o a la acción de consentir con palabras tiernas a un bebé o una mascota, hacía que los niños de manera casi imperceptible elevaran su registro. Este trabajo resultó muy divertido para todos, ya que no es común imitar acciones de la propia cotidianidad en la que ellos elevan el registro de su voz hablada. En este sentido el trabajo ayudó a crear conciencia sobre el trabajo técnico en las notas agudas, y a su vez esta metodología de enseñanza permitió la amplitud de la tesitura del grupo (Pérez, 2015).

A lo largo de este trabajo también se logró identificar que existe una relación entre corporeidad y afinación; relación ya descubierta por Kodaly (Zuleta, 2013), pues aunque el sonido de la voz procede del aparato fonador, el acto de pensar afinadamente parte de dimensionar, imaginar y asociar la afinación a través del movimiento de las distintas partes del cuerpo. Por esta razón, el trabajo eurítmico generado con los estudiantes en este trabajo coral les permitió alcanzar un nivel satisfactorio en cuanto a afinación se refiere.

\section{La relación entre escenario y responsabilidad}

De igual forma, el trabajo colectivo coral permitió a los investigadores generar un reconocimiento en torno a las necesidades de un contexto, así como construir una teoría en torno a la relación música-cuerpo. En cuanto a los niños, el ejercicio facultó observar el desarrollo de algunas cualidades humanas, entre las cuales sobresalieron la responsabilidad y la autodeterminación, que se observaron una vez inició el proceso del montaje de las obras, pues cada uno de los integrantes del coro empezó a desarrollarlas desde su propio sentido de identidad musical (Samper, 2010) para relacionarse con los demás, a través de su actuar en el montaje musical, por medio de las canciones y los correspondientes movimientos. Lo anterior generó una re-significación de la actividad coral euritmica, pues como se pudo observar, mucho más allá de cantar y moverse, esta trata, en este caso, de la actitud de los niños durante el tiempo que permanecen en el aula. El traslado al aula múltiple, donde se realizaban los ensayos, fue uno de los momentos en los que se generó una re-significación en torno a los sentidos de responsabilidad, ya no coercitiva de parte del docente, sino voluntaria por parte de ellos; si bien se aprendieron ciertos ideales, en términos de la formación de los estudiantes como ciudadanos (Cortina, 2009) los autores coincidimos con Ramos y Conde (2015), cuando afirman que

\footnotetext{
Las nuevas pedagogías del cuerpo son el eje vertebral de una pedagogía crítica centrada en la corporeidad, pues es a partir de las propuestas que se generan en los espacios pedagógicos que se da la resistencia, al confrontar las estructuras objetivas de los participantes del estudio. (p. 77).
} 
La práctica descrita en este artículo reformula, de una u otra manera, no solo la práctica y la dirección coral, sino también las relaciones de poder en la escuela, pues este ya no proviene de la autoridad (Quiceno, 2015), sino (quitaría esto último porque aquí se demuestra que el maestro es una autoridad que sabe su materia y sabe de la formación, diferente al autoritarismo) > , a partir de un saber musical sensorial y lúdico, en donde se pone de manifiesto al mismo tiempo el saber-hacer y el disfrutar de la experiencia corpórea. Se da por sentado entonces que en esta práctica se expone una nueva forma de dirección coral, en la cual el director forma parte de la euritmia. En otras palabras, en este modelo de trabajo el director no indica lo que "se debe hacer", sino que exterioriza aquello que "el coro y yo estamos haciendo", hecho que posibilita una sana convivencia desde la propia experiencia (Unda y Gutiérrez, 2015). Si se tratara de responder en el ámbito académico a la pregunta formulada por los estudiantes del curso sobre "¿Por qué nos escogió a nosotros para la práctica coral, si somos tan indisciplinados?", una posible respuesta sería que la investigación cualitativa experimental en términos de la euritmia en el coro infantil llegó a convertirse en una actividad transformadora dentro del aula escolar, que ofreció a los niños involucrados en el montaje una visión más amplia de sus propias capacidades humanas, expresivas, musicales y comunicativas, así como la capacidad para verse incluidos en una tarea comunitaria y artística; a estos niños se les escogió por su entusiasmo y deseo por la libertad. Y porque, quizás, ha llegado el momento histórico de indisciplinar la práctica coral.

\section{Referencias}

Ácaso, M. (2013). Reduvolution. Madrid: Paidós Ibérica.

Berger, P. y Luckmann, T. (1995). La construcción social de la Realidad. Buenos Aires: Amorrortu.

Burkholder, P. (2008). Historia de la Música Occidental. Madrid: Alianza.

Carlgren, F. (1989). Pedagogía Waldorf, una educación hacia la libertad. Madrid: Editorial Rudolph Steiner.

Cerón, J. (2012). El arte como investigación. Praxis y Saber, 231-238.

Clouder, C. y Rawson, M. (2002). Educación Waldorf. Madrid: Editorial Rudolf Steiner.

Cortina, A. (2009). Ciudadanos del mundo. Hacia una teoría de la ciudadanía. Madrid: Alianza Editorial.

Díaz Barriga, Á. (2005). El docente y los programas escolares. Lo institucional y lo didáctico. Barcelona: Palomares Editores.

Durán, M. (2011). La escritura en las disciplinas artísticas. Cuadernos de Música, Artes Visuales y Artes Escénicas, 6, 5.

Errenst, M. (2012). Los doce sentidos. Recuperado de http:// errenst.eu

Foucault, M. (2003). Vigilar y castigar. Buenos Aires: Siglo xxı. Freire, P. (1975). Pedagogía del oprimido. Siglo xxl: Madrid.

Gardner, H. (1997). Arte, mente y cerebro. Una aproximación cognitiva a la creatividad. Paidós: Madrid.

Grau, O., Ortega, F., Celedón, G. y Oyarzún, E. (Eds.). (2014). La instancia en la música. Santiago: Universidad Metropolitana de Ciencias de la Educación.

Marcos, M. (2014). Historia y actualidad de la pedagogía Waldorf (trabajo de grado) Universidad de Valladolid, Valladolid

Mejía, M. (2014). Naturaleza y sentido del trabajo del maestro y la maestra en el Siglo XXl. Anotaciones para contribuir al debate sobre el Estatuto Docente. Nodos y Nudos, 4, 37, 5-20. 
Morales, P. (2009). La euritmia como recurso pedagógico en la formación coral de niños y jóvenes en Venezuela (trabajo de grado). Universidad Simón Bolivar, Caracas, Venezuela.

Muñoz, P. (2005). El arte en la educación no sirve para "nada". Nodos y Nudos, 2(18).

Narodowski, M. (2013). Hacia un mundo sin adultos. Infancias híper- y desrealizadas en la era de los derechos del niño. Actualidades Pedagógicas, 62, 15-36.

Pasek, E. (2008). La construcción del problema de investigación y su discurso. Ponencia presentada en el Primer Encuentro Doctoral de la Universidad Fermin Toro Febrero, 2008. Universidad Fermin Toro: Cabudare, Venezuela.

Pérez, M. (2015). Aplicación de la euritmia en el coro infantil del grado quinto $B$ de la Escuela Normal Superior de Popayán (tesis de grado). Universidad del Cauca, Popayán, Colombia.

Quiceno, H. (2015). El maestro, la investigación y la estrategia pedagógica [video]. Recuperado de https://www.youtube.com/watch?v=IS1AwT8c2H4

Quiroga, P. (2014). La pedagogía Waldorf: origen, consolidación internacional y principios educativos. Bogotá: FahrenHouse.

Ramos, E. y Conde, G. (2015). Nuevas pedagogías del cuerpo para la transformación de las subjetividades subordinadas en subjetividades emancipadas. Cuadernos de Música, Artes Visuales y Artes Escénicas, 1, 77.
Restrepo, S. (2005). Aproximación al teatro musical y a la música conceptual a través del análisis estético, estilistico y estructural de los holas, música- etc. 1966 en tres tiempos, de Juan Hidalgo. Cuadernos de Música, Artes Visuales y Artes Escénicas, 12, 28.

Samper, A. (2010). La apreciación musical en edades juveniles: territorios, identidad y sentido. Cuadernos de Música, Artes Visuales y Artes Escénicas, 5, 31.

Shifres, F. (2012). Más allá de lo sonoro: la música, sus límites y vinculaciones desde una lectura psicológica. Cuadernos de Música, Artes Visuales y Artes Escénicas, 7, 5-10.

Tetamanti, M. y Escudero, B. (comps). (2012). Cartografía Social. Buenos Aires: Ministerio de Educación de la Nación. República Argentina.

Toch, E. (2001). Elementos constitutivos de la música: armonía, melodía, contrapunto y forma. Barcelona: Idea Books.

Unda, M.P. y Gutiérrez, A. (2015). Viajes y encuentros pedagógicos como experiencias de formación de maestros. Nodos y Nudos, 4 (39), 7-26.

Wallerstein, I. (2006). Abrir las ciencias sociales. Madrid: Siglo xxl.

Zuleta, A. (2013). El método Kodaly. Cuadernos de Música, Artes Visuales y Artes Escénicas, 1, 37.

Zuluaga, 0. (1999). Pedagogía e Historia. Antioquia: Anthropos. 


\section{DIÁLOGO DEL CONOCIMIENTO}

Es una experiencia reveladora. Nos plantea la posibilidad de recuperar los seres de manera integral en las actividades escolares. Creo que, además, se adelanta en un ámbito en el que el éxito colectivo depende mucho de la participación "disciplinada" y "obediente" de cada uno de los integrantes.

Ya lo manifiestan los autores en el desarrollo del escrito. Se está adelantando una actividad que contradice los presupuestos de la escuela convencional; y en ello se corrobora que, más allá de los reglamentos y controles que se suelen utilizar para lograr no solo la realización de las actividades previstas, sino la participación creativa y entusiasta en ella, de lo que se requiere es del reconocimiento de los actores como personas integrales, con sus cualidades y comportamientos -si se quiere divergentes, pero auténticos-. Además, no se trata solo de repetir y memorizar, sino de crear y de convertir las exigencias en ocasiones de realización personal, en las que lo que se logra lleva el sello de los niños, no como simples ejecutores obedientes sino como participantes a la vez inteligentes y alegres.

Ahora bien, vale la pena recalcar que los niños son conscientes de la divergencia de su comportamiento frente a las exigencias usuales de "disciplina", y que para ellos algo está cambiando positivamente cuando, a pesar de ser lo que son y de hacer lo que hacen, son reconocidos como ejemplares en la consecución de lo que se busca. Esa conciencia de que la escuela puede ser distinta, y en ese sentido amigable y plena de significados, es lo que seguramente puede salvarla ante las dictaduras que proceden de las arbitrariedades y controles de esa escuela anacrónica que encontramos por todas partes.

Dino Segura 